\title{
Preliminary study to assess mycotoxin concentrations in whole corn in the California feed supply
}

\author{
N. D. Krout-Greenberg, ${ }^{\star} \dagger$ B. Puschner, $\ddagger$ M. G. Davidson, $†$ and E. J. DePeters* $\S^{1}$ \\ *Nutritional Biology Graduate Group, University of California, Davis 95616 \\ †California Department of Food and Agriculture, Feed, Fertilizer and Livestock Drugs Regulatory Services, \\ Safe Animal Feed Education (SAFE) Program, Sacramento, CA 95814 \\ ‡Department of Molecular Biosciences and the California Animal Health and Food Safety Laboratory, School of Veterinary Medicine, and \\ $\S$ Department of Animal Science, University of California, Davis 95616
}

\begin{abstract}
Mycotoxins are naturally occurring environmental contaminants recognized worldwide in a variety of food and feed products. Produced as secondary metabolites by filamentous fungi, mycotoxins can have acute and chronic effects. Differing seasonal weather patterns and harvesting and storage conditions put corn grain at high risk for mycotoxin contamination. The objective of this study was to assess the risk of mycotoxin exposure posed to California livestock from whole corn. Random samples $(\mathrm{n}=50)$ of whole corn were collected and analyzed for 6 different mycotoxins, including aflatoxins, fumonisins, ochratoxins, trichothecenes (deoxynivalenol and T-2 toxin), and zearalenone. The samples represented a cross section of the corn entering California from various corn-growing states $(\mathrm{n}=43)$ as well as additional samples from California-grown corn ( $\mathrm{n}=$ 7). The experiment was a randomized sampling design. Over the course of a 6 -mo period, 16 trains in California (100-110 railcars) and 5 California grain elevators were randomly sampled. Aflatoxins were detected in 14 samples, with 1 sample containing a concentration of $41.3 \mu \mathrm{g} / \mathrm{kg}$ (as-is basis), which was above the action level of $20 \mu \mathrm{g} / \mathrm{kg}$ for corn fed to dairy cattle. The average concentration of aflatoxins for the 13 samples below the regulatory action level was $8.69 \mu \mathrm{g} / \mathrm{kg}$ (range 4.67 to $13.82 \mu \mathrm{g} / \mathrm{kg}$ ). Deoxynivalenol was found in 15 samples and averaged $553 \mu \mathrm{g} / \mathrm{kg}$ (range 340 to 1,072 $\mu \mathrm{g} / \mathrm{kg}$ ), which was below the federal advisory level of $5,000 \mu \mathrm{g} / \mathrm{kg}$ for grain fed to dairy cattle. Fumonisins were found in 38 samples and averaged $1,687 \mu \mathrm{g} / \mathrm{kg}$ (range 435 to $4,843 \mu \mathrm{g} / \mathrm{kg}$ ), which was below the federal guidance level of $30,000 \mu \mathrm{g} / \mathrm{kg}$ in corn for dairy cattle. Ochratoxins, T-2 toxins, and zearalenone were not detected in any samples of whole corn. Fumonisins were the most prevalent mycotoxins found.
\end{abstract}

Received July 18, 2012.

Accepted December 15, 2012.

${ }^{1}$ Corresponding author: ejdepeters@ucdavis.edu
Key words: corn, deoxynivalenol, fumonisin, mycotoxin

\section{INTRODUCTION}

Mycotoxins are secondary metabolites produced by fungi that pose a continual threat to producers and manufactures of livestock feeds as well as foods for humans (Yiannikouris and Jouany, 2002; Balázs and Schepers, 2007; Bryden, 2012). Their deleterious effects have a long history dating back centuries (Yiannikouris and Jouany, 2002; Richard, 2007). Approximately $25 \%$ of the world's food supply is contaminated by mycotoxins annually (Richard et al., 2003) with corn (maize) being one of the food supplies of greatest concern (Rodríguez-Amaya and Sabino, 2002; Wild and Gong, 2010; Rodrigues and Naehrer, 2012). Fumonisins were found in a variety of corn-based food products commercially sold in Brazil (Caldas and Silva, 2007). In addition to corn, other cereals, peanuts, and tree nuts often contain mycotoxins in low-income countries, with aflatoxins and fumonisins the prevalent mycotoxins (Wild and Gong, 2010). Indeed, the importance of mycotoxins in foods is illustrated by the fact that the World Mycotoxin Journal devoted a special issue to Fusarium mycotoxins [e.g., deoxynivalenol (DON), T-2/HT-2 toxins, and zearalenone (ZEN)] and their effects on human health (Shephard et al., 2010) and that an international workshop entitled "Mycotoxins from the Field to the Table" was held in 2006 (Balázs and Schepers, 2007).

Mycotoxins are also of concern in the feed supply of livestock industries because of their ability to cause acute and chronic toxic effects, leading to illnesses and subsequent vast economic losses. A survey of feedstuffs on 24 dairy farms in the Netherlands found that DON, ZEN, roquefortine $\mathrm{C}$, and mycophenolic acid had the highest prevalence (Driehuis et al., 2008). A 2-yr survey of feedstuffs sampled at the farm and feed manufacturer levels in the European/Mediterranean markets (1,507 samples) and the Asian-Pacific region (1,291 samples) 
revealed that DON, ZEN, and T-2 toxin were the major mycotoxins in the European feed samples and DON, ZEN, fumonisins, and aflatoxins in the Asian-Pacific region (Binder et al., 2007). Mycotoxins are clearly a specific concern in corn (Binder et al., 2007; Wild and Gong, 2010). Seventy percent of the corn samples from the Asian-Pacific region were contaminated with DON, $69 \%$ were contaminated with fumonisins, and $41 \%$ were contaminated with ZEN (Binder et al., 2007). For European samples of corn, 81,63 , and $56 \%$ were found to be contaminated with DON, ZEN, and fumonisins, respectively. Mycotoxin levels are seasonally variable in corn crops due to environmental conditions, particularly during the growing season. Seasonal differences in mycotoxin contamination of corn were recently reported in a German study (Goertz et al., 2010). Corn grown with high temperature and low rainfall conditions resulted in $75 \%$ of the corn samples contaminated with DON, $34 \%$ with fumonisins, and $27 \%$ with ZEN. In the following year with moderate temperatures and frequent rainfall events, $90 \%$ of the corn samples had DON and 93\% had ZEN, but no fumonisin-positive samples were detected. However, improper harvesting and storage can also cause rapid formation of mycotoxins after harvest. Storing moist corn for $7 \mathrm{~d}$ following harvest before drying significantly increased the concentrations of fumonisins and ZEN (Magan and Aldred, 2007). Corn is often harvested at moisture contents greater than 14 to $15 \%$, but this requires subsequent drying of the grain to reduce the available water to less than 0.70 water activity $\left(\mathrm{a}_{\mathrm{w}}\right)$ to allow safe storage of the corn (Magan and Aldred, 2007).

The amount of corn used in California has steadily increased. Corn is used by the dairy and livestock industries and, more recently, large amounts of corn are used by the ethanol industry to produce alcohol for fuel purposes. California has a grain production-use deficit of almost 4.82 million tonnes (Cothern, 2000). Thus, to meet the corn demand, California imports corn from other states. One of the largest imported feed commodities into California is corn. In 2003, corn shipped into California from Iowa and Nebraska accounted for $72 \%$ of California's corn supply needs. Recent information obtained through way bill sample data shows that the amount of corn being railed into the San Joaquin Valley of California is over 4 times larger than local corn production (California Grain Foundation, 2005).

Corn is grown for grain in the Northern San Joaquin Valley in Central California, with little corn grain production in the Southern San Joaquin and Imperial Valleys. Most of the corn imported into California is produced in the Midwest. Quality components to monitor for imported corn are mycotoxins because they can elicit toxic responses (mycotoxicosis) in animals and humans. Mycotoxins or their metabolites, or both, can be found in milk (González-Osnaya et al., 2008) and meat, which, if consumed, can have detrimental effects on human health (Yiannikouris and Jouany, 2002; Wild and Gong, 2010). However, no information exists on the mycotoxin contamination of corn imported into California.

It is evident that it is impossible to fully eliminate the presence of mycotoxins in feeds and food. Thus, it is important to assess mycotoxin concentrations and compare them to scientifically sound maximum concentrations. The objective of this preliminary study was to assess the concentrations of mycotoxins in whole corn destined to be fed to California livestock.

\section{MATERIALS AND METHODS}

\section{Sample Collection}

Fifty random samples $(\mathrm{n}=50)$ of whole corn were collected and analyzed for 6 different mycotoxins. The corn samples $(n=43)$ represented a cross section of the corn entering California from various corn-growing states, including Nebraska, Iowa, Michigan, and South Dakota via the Union Pacific and the Burlington Northern Santa Fe rail lines, as well as additional samples $(\mathrm{n}=7)$ from corn grown in California. The grain elevators sampled for California grown corn were in the California cities of Petaluma, Stockton, and Williams. Information on agronomic growing and harvesting conditions was not collected.

During a 6-mo time period (March 2006 through September 2006), 16 unit trains (100 to 110 railcars per unit train) delivering products into California and 5 grain elevators in California were randomly sampled for corn by special investigators of the California Department of Food and Agriculture (CDFA) Feed, Fertilizer, and Livestock Drugs Regulatory Services Branch (Sacramento). All investigators used official CDFA methods of sampling. Three railcars were chosen at random from each unit train and sampled using the CDFA commercial feed sampling methods (CDFA, 1997). Briefly, the CDFA bulk corn sampling method involved using either a Seedburo model 815, 8-foot (2.4-m) partitioned with 16 openings, grain probe (Seedburo Equipment Co., Des Plaines, IL) or a 500-mL stream cutter, 6-foot (1.8-m) handle, polyethylene sample dipper (Fisher Scientific, Pittsburg, PA). In the event that samples were obtained using the compartmented grain probe, a minimum of 3 cores per railcar or truck were gathered. Similarly, a composite sample of 20 stream cuts was obtained while the railcar or truck was unloading. Three railcars were chosen at random from each unit train and sampled as described. Samples were collected 
while the railcar or truck was being unloaded to ensure chain of custody, which involves collecting information of sample origin and special investigator identification to follow sample processing and analysis in various laboratories. Information was obtained on the city or town and state of origin of the grain as well as the local manufacturer for each sample. Samples were packaged in 4-mL polyethylene plastic bags and sent overnight to the CDFA Center for Analytical Chemistry. At the Center for Analytical Chemistry, the entire whole corn sample was coarse ground using a Jacobson Grinder (model P-88 B Pulverator; Carter Day International Inc., Minneapolis, MN), and then fine ground using the Retsch Mill (model ZM 200 Ultra Centrifugal Mill; Retsch Inc., Newton, PA). Subsamples were analyzed for moisture by drying at $100^{\circ} \mathrm{C}$; however, only 18 samples were analyzed for moisture. The average value for moisture was used for all corn samples. A second set of subsamples $(700 \mathrm{~g})$ was placed into Whirl-Pak plastic bags (Nasco, Fort Atkinson, WI) and frozen at $-20^{\circ} \mathrm{C}$ until mycotoxin analysis.

\section{Sample Extraction}

Extraction procedures for mycotoxins from corn were performed in batches. A total of 50 corn samples were grouped into 5 batches of 10 samples each. Each batch included a control sample and fortifications (spikes) at the mycotoxin detection limits (Tables 1 and 2). For analysis for aflatoxins, fumonisins, trichothecene T-2 toxins, and ochratoxins, $20 \mathrm{~g}$ of finely ground corn sample was extracted with $100 \mathrm{~mL}$ of $70 \%$ methanol (MeOH) in water $(1: 5, \mathrm{wt} / \mathrm{vol})$ with $\mathrm{NaCl}(4 \mathrm{~g}$ of $\mathrm{NaCl}$ dissolved in $30 \mathrm{~mL}$ of water and added to $70 \mathrm{~mL}$ of $\mathrm{MeOH})$. For DON analysis, $20 \mathrm{~g}$ of ground corn sample was extracted with $100 \mathrm{~mL}$ of distilled water. Each sample was shaken for $10 \mathrm{~min}$ and centrifuged at $195 \times$ $g$ for $3 \mathrm{~min}$. Supernatants were filtered through Whatman no. 4 filter paper. The aflatoxin and ochratoxin extracts were immediately analyzed following filtration. The filtrates for DON (1:4), fumonisin (1:20), and T-2 toxin (1:10) required further dilutions in water at the indicated ratios. The filtrate for ZEN analysis was diluted 1:5 in $70 \% \mathrm{MeOH}$ in water. Prepared standards in matrix (control negative corn) were used for quantification. The standards in matrix, corn sample extracts, and fortified samples were analyzed using ELISA kits with well-to-well duplications.

Extraction and analysis of corn samples by liquid chromatography-tandem mass spectrometry (LC-MS/ MS) was performed according to the California Animal Health and Food Safety Laboratory System standard operating procedure, slightly modifying a previously published method (Spanjer et al., 2008). Briefly, for

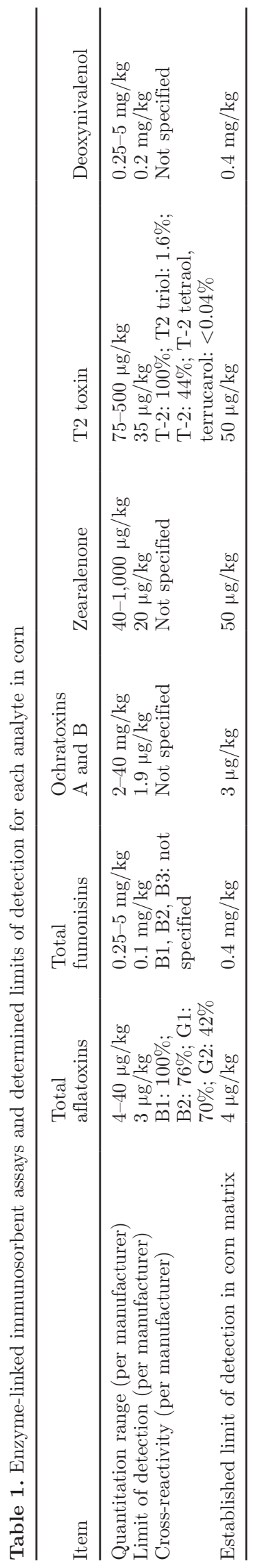

Journal of Dairy Science Vol. 96 No. 4, 2013 


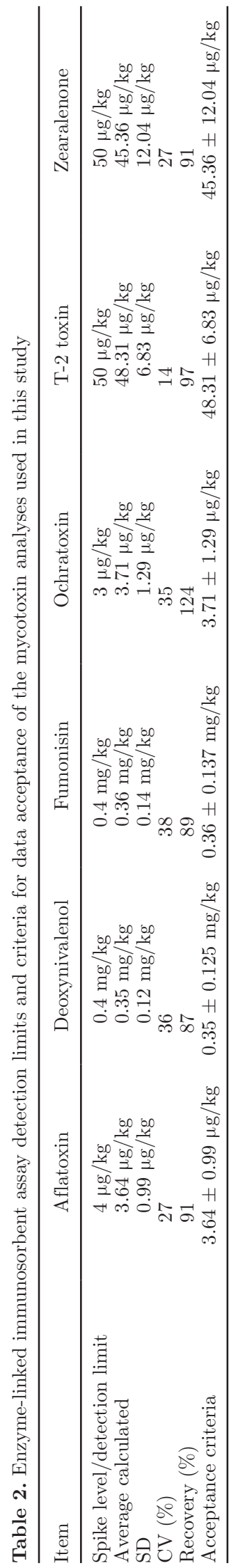

aflatoxin $\mathrm{B}_{1}$ and DON analyses, $10 \mathrm{~g}$ of ground corn sample was extracted with $40 \mathrm{~mL}$ of acetonitrile/water (84:16; vol/vol). After solid-phase extraction clean-up (MycoSep 226 SPE; Romer Labs Inc., Union, MO), 4 $\mathrm{mL}$ of purified extract was evaporated to dryness and reconstituted in $0.4 \mathrm{~mL}$ of methanol/water $(1: 1 \mathrm{vol} /$ vol) and subjected to LC-MS/MS analysis. For fumoni$\sin \mathrm{B}_{1}$ analysis, $5 \mathrm{~g}$ of ground corn was extracted with $50 \mathrm{~mL}$ of methanol in water $(75: 25$; vol/vol), filtered, and analyzed by LC-MS/MS.

\section{Mycotoxin Analysis}

Samples were analyzed using established and commercially available ELISA kits (Romer Labs Inc.; Table 1). Method acceptance criteria were performed as follows: each analyte was evaluated in 21 individual analyses (7 samples per day on 3 separate days). Each analyte was added to a negative control sample (corn) at specific ELISA detection limits. Method detection limits (MDL), expressed on an as-is basis, were as follows (Table 1$)$ : total aflatoxins $(\mathrm{MDL}=4 \mu \mathrm{g} / \mathrm{kg})$, total fumonisins ( $\mathrm{MDL}=400 \mu \mathrm{g} / \mathrm{kg})$, ochratoxin A and B $(\mathrm{MDL}=3 \mu \mathrm{g} / \mathrm{kg}), \mathrm{ZEN}(\mathrm{MDL}=50 \mu \mathrm{g} / \mathrm{kg}), \mathrm{T}-2$ toxin $(\mathrm{MDL}=50 \mu \mathrm{g} / \mathrm{kg})$, and DON $(\mathrm{MDL}=400 \mu \mathrm{g} / \mathrm{kg})$. Data were accepted only if criteria of acceptance were met (Table 2).

Results were gathered in the following manner: positive samples from the first ELISA run were reextracted and analyzed by ELISA again. If the second run and the first run differed by more than $20 \%$, a third reextraction and reanalysis was performed. All analyses included control samples. All samples determined positive by ELISA were analyzed by LC-MS/MS to confirm the presence of mycotoxin analytes. Liquid chromatography-tandem mass spectrometry analysis was performed on an AB Sciex 4000 QTrap LC-MS/MS system (AB Sciex, Framingham, MA) equipped with a Luna C18 HPLC column (Phenomenex Inc., Torrance, CA). Quality control samples included control corn (free of mycotoxins), reagent blanks, and corn samples fortified with 5 to $20 \mu \mathrm{g}$ of aflatoxin $\mathrm{B}_{1} / \mathrm{kg}, 0.25$ to $0.5 \mathrm{mg}$ of $\mathrm{DON} / \mathrm{kg}$, and 0.5 to $1 \mathrm{mg}$ of fumonisin $\mathrm{B}_{1} /$ $\mathrm{kg}$. Each mass spectrum was evaluated and compared with those of referenced analytical standards. Negative results by ELISA were not confirmed by LC-MS/ MS. Although it is known that ELISA kits have the potential for false-negative results due to inhibition of the ELISA antibodies by matrix components, if done accordingly, ELISA assays generally have false-negative rates of $<5 \%$ (De Saeger et al., 2002). This low falsenegative rate is acceptable when considering the cost savings by using ELISA versus chromatography analytical techniques for screening purposes. 


\section{RESULTS}

Mycotoxin concentrations were expressed as means and the detected concentration range was provided. Corn samples obtained from out of state had origins in Nebraska, Minnesota, Iowa, and South Dakota. The local grain elevators sampled were all located in Northern California.

Aflatoxins were detected in 14 samples (Table 3), with 1 sample, which was from California, containing a concentration of $41.3 \mu \mathrm{g} / \mathrm{kg}$, which was above the federal action level for corn fed to dairy cattle of $20 \mu \mathrm{g} / \mathrm{kg}$. The average concentration of aflatoxins for the other 13 samples was below the regulatory level and averaged $8.69 \mu \mathrm{g} / \mathrm{kg}$, with a range of 4.67 to $13.82 \mu \mathrm{g} / \mathrm{kg}$. No aflatoxins were detected in the remaining 6 samples of whole corn grown in California.

Deoxynivalenol was found in 15 samples and averaged $553 \mu \mathrm{g} / \mathrm{kg}($ range $=340-1,072 \mu \mathrm{g} / \mathrm{kg}$; Table 3 ), which was below the federal advisory level of $5,000 \mu \mathrm{g} /$ $\mathrm{kg}$ for dairy cattle. Deoxynivalenol was not detected in any of the whole corn samples that were grown in California.

Fumonisins were found in 38 samples and averaged $1,687 \mu \mathrm{g} / \mathrm{kg}$ (range $=435-4,843 \mu \mathrm{g} / \mathrm{kg}$; Table 3 ), which again was below the Federal guidance level of 30,000 $\mu \mathrm{g} / \mathrm{kg}$ for corn offered to dairy cattle. Four of the whole corn samples from California contained fumonisins and averaged $2,628 \mu \mathrm{g} / \mathrm{kg}($ range $=454-4,461 \mu \mathrm{g} / \mathrm{kg})$. For the samples of corn grown in California, fumonisin was the mycotoxin found in greatest prevalence. Ochratoxins, T-2 toxin, and ZEN were not detected in any of the 50 whole corn samples (Table 3). For all ELISA-positive analyses, specific LC-MS/MS analysis confirmed the presence of the respective mycotoxins.

\section{DISCUSSION}

In California, more than $85 \%$ of corn grain used comes from out of state. Many of the supplying states experience growing and storage conditions that favor mold growth and mycotoxin contamination. Thus, to ensure a safe food and feed supply, it is important to detect agricultural commodities contaminated with mycotoxins before they pose a significant health risk to livestock/dairy animals, companion animals, and humans.

California Department of Food and Agriculture's Feed and Livestock Drug Inspection Program monitors feed commodities that may pose a threat to the feed or food supply in California. The present data provides an estimate of the prevalence of mycotoxin contamination in corn samples shipped to, and grown in, California. Fumonisins were the most prevalent mycotoxin found,

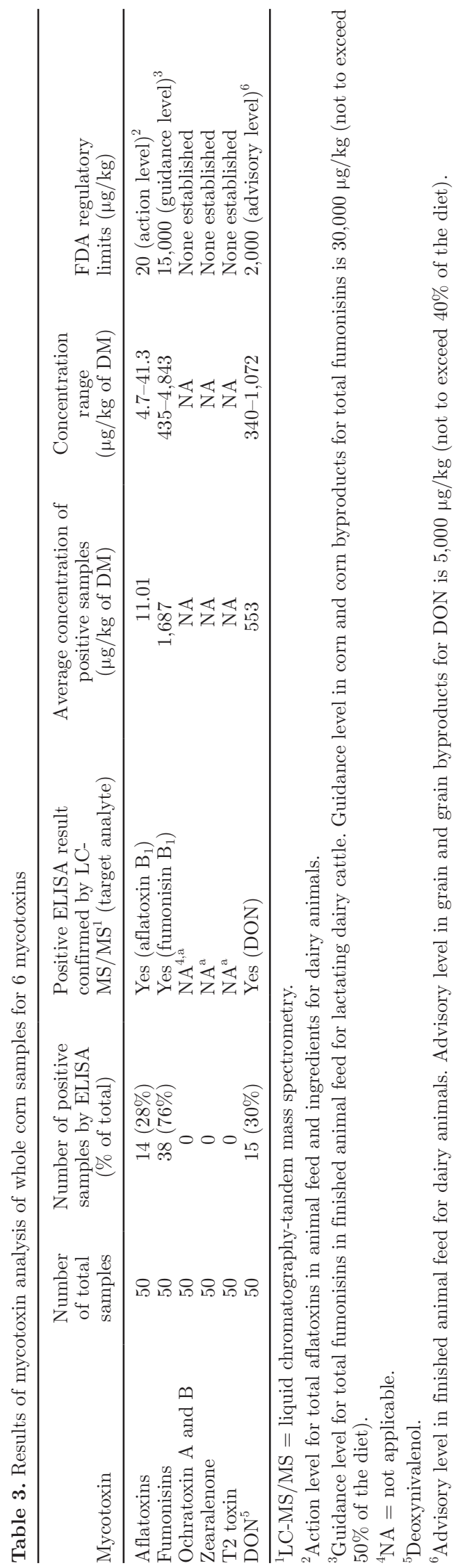

Journal of Dairy Science Vol. 96 No. 4, 2013 
with 38 positive results out of 50 samples $(76 \%$ contaminated samples). The average concentration of fumonisins was $1,687 \mu \mathrm{g} / \mathrm{kg}$, with the highest concentration $(4,843 \mu \mathrm{g} / \mathrm{kg})$ found well below the Food and Drug Administration (FDA) guidance level of $15,000 \mu \mathrm{g} /$ $\mathrm{kg}$ in finished feeds for lactating cows and $30,000 \mu \mathrm{g} /$ $\mathrm{kg}$ in corn and corn byproducts. Four of the 7 samples $(57 \%)$ of corn grown in California were contaminated with fumonisins, averaging $2,280 \mu \mathrm{g} / \mathrm{kg}$. Rheeder et al. (2002) reported 28 fumonisin (FB) analogs characterized, with the most prevalent being $\mathrm{FB}_{1}$, but $\mathrm{FB}_{2}$, and $\mathrm{FB}_{3}$ were also important. Fumonisins $\mathrm{B}_{1}\left(\mathrm{FB}_{1}\right)$ was the most prevalent mycotoxin in unprocessed corn in Brazil (Vargas et al., 2001) with 99\% of the samples contaminated (212 positive out of 214 tested), with a mean $\mathrm{FB}_{1}$ concentration of $2,200 \mu \mathrm{g} / \mathrm{kg}$ ( range $=200-6,100 \mu \mathrm{g} /$ $\mathrm{kg}$ ). Similar results were found by Binder et al. (2007) who reported that $69 \%$ (213 positive out of 309 total tested) of the corn samples from the Asian-Pacific region that were tested for fumonisins were contaminated $($ mean $=1,335 \mu \mathrm{g} / \mathrm{kg})$. For corn samples from the European region, $56 \%$ (9 out of 16 samples) were contaminated (mean $=836 \mu \mathrm{g} / \mathrm{kg}$ ) with fumonisins. Regional differences in fumonisin contamination of corn in Brazil were associated with climatic conditions during the growing season (Ono et al., 1999). Higher fumonisins occurred with higher rainfall the month before harvest. Fumonisins were found in grains and grain products worldwide (Rodrigues and Naehrer, 2012). By ELISA, $45 \%$ positive samples of corn for fumonisins $\left(\mathrm{FB}_{1}, \mathrm{FB}_{2}\right)$ were found worldwide, with a mean concentration of $813 \mathrm{mg} / \mathrm{kg}$ (Rodrigues and Naehrer, 2012; Scott, 2012). The observations of these studies agree with the findings of the current study that fumonisins are prevalent mycotoxins in corn. Based on the results from the present study, the California Feed Inspection Program now routinely screens for fumonisins in all feed containing corn grain.

In the present study, $30 \%$ of the corn samples had detectable concentrations of DON (mean concentration $=553 \mu \mathrm{g} / \mathrm{kg}$ ) and $28 \%$ had detectable concentrations of aflatoxins (mean concentration $=11.01 \mu \mathrm{g} / \mathrm{kg}$ ), but even the highest detected concentrations were below the FDA advisory or action limits. In contrast, to the present observations for DON, Binder et al. (2007) reported much higher prevalence of contamination and higher mycotoxin concentrations in corn samples. These researchers reported that $70 \%$ (219 out of 312 samples) and $81 \%$ (197 out of 244 samples) were contaminated with DON from the Asian-Pacific and European regions, respectively. The concentration of DON averaged 1,104 $\mu \mathrm{g} / \mathrm{kg}$ for the Asian-Pacific region and $1,073 \mu \mathrm{g} / \mathrm{kg}$ for the European region. Worldwide, for 459 corn samples tested, $78 \%$ were positive for DON (mean concentration
$=742 \mathrm{mg} / \mathrm{kg}$; Rodrigues and Naehrer, 2012). This is in agreement with the high incidence reported by Binder et al. (2007). In a review of mycotoxins found in Brazil, DON was not detected in corn (0 positive samples out of 130 samples tested) for the 1991 crop year, but in the crop year 1994 to 1995 , DON was detected in 7 out of 115 samples tested and the concentration ranged from 102 to $542 \mu \mathrm{g} / \mathrm{kg}$. Climatic conditions affect the growth of fungi (Yiannikouris and Jouany, 2002). Indeed, higher concentrations of DON were found on corn grown in moderate temperatures and frequent rainfall $(2,240 \mathrm{ng} / \mathrm{g})$ compared with corn grown at high temperature and low rainfall $(1,780 \mathrm{ng} / \mathrm{g}$ ) (Goertz et al., 2010). Thus, growing conditions in the Midwest and California will likely have an effect on DON prevalence. Contaminated grains with DON concentration above 1 $\mu \mathrm{g} / \mathrm{g}$ were reported to be potentially harmful to swine (Richard, 2007).

In Brazil, $38 \%$ of corn samples were positive for total aflatoxins $($ mean $=11 \mu \mathrm{g} / \mathrm{kg}$; range $=0.4$ to $139 \mu \mathrm{g} /$ $\mathrm{kg}$; Vargas et al., 2001). Aflatoxin $\mathrm{B}_{1}$ was the major form contributing to total aflatoxins in prevalence and concentration compared with $\mathrm{B}_{2}, \mathrm{G}_{1}$, and $\mathrm{G}_{2}$. In the Asia-Pacific region, $17 \%$ (54 out of 311 samples) and for the European region, 21\% (3 out of 14 samples) of samples were positive for aflatoxin $\mathrm{B}_{1}$ (Binder et al., $2007)$. Only the mean concentration for aflatoxin $B_{1}(60$ $\mu \mathrm{g} / \mathrm{kg}$ ) was reported. In a 10-yr review of mycotoxins in foods and feeds in Brazil (Rodrigues and Naehrer, 2012), aflatoxins were not found in the 1992 to 1993 crop year in corn and only 1 positive sample out of 130 was found in the 1991 crop year. But in the crop year 1993 to 1994, aflatoxin $\mathrm{B}_{1}$ (97 positive out of 292 total samples tested) and $\mathrm{B}_{2}$ (33 positive out of 202 total samples) were found. Aflatoxin $\mathrm{B}_{1}$ concentration ranged from 2 to $89 \mu \mathrm{g} / \mathrm{kg}$ and $\mathrm{B}_{2}$ ranged from 1 to 17 $\mu \mathrm{g} / \mathrm{kg}$. Aflatoxin $\mathrm{G}$ was also found in corn in 2 studies and ranged in concentration across studies from 1 to $85 \mu \mathrm{g} / \mathrm{kg}$. Rodrigues and Naehrer (2012) reported a low incidence of $8 \%$ positive samples for aflatoxins $\left(\mathrm{B}_{1}, \mathrm{~B}_{2}, \mathrm{G} 1\right.$, and $\left.\mathrm{G}_{2}\right)$ out of 50 samples tested. In the present study, total aflatoxins $\left(\mathrm{B}_{1}, \mathrm{~B}_{2}, \mathrm{G}_{1}\right.$, and $\left.\mathrm{G}_{2}\right)$ were measured, which does not allow direct comparison to individually estimated aflatoxin concentrations. However, our study shows only a slightly higher prevalence (28\%) than Binder et al. (2007), and concentrations are in the range of those reported by others.

Ochratoxins, T-2 toxin, and ZEN were not detected in whole corn sampled in the present study. The prevalence of ochratoxin A in corn appeared to differ by world region. In a study in Brazil, 31\% of corn samples were contaminated with ochratoxin A, with concentrations ranging from 4.9 to $132.0 \mu \mathrm{g} / \mathrm{kg}$ (Magnoli et al., 2007). In the Asian-Pacific region, ochratoxin A was detected 
in $25 \%$ (9 out of 36 samples) of the samples, averaging $20 \mu \mathrm{g} / \mathrm{kg}$ (Binder et al., 2007). In contrast, ochratoxin A was not detected in corn samples from the European region, which agrees with our observations of negative results for ochratoxin $\mathrm{A}$ and $\mathrm{B}$ in corn samples either from out of state or grown within CA. The T-2 toxin was also not found in corn samples from the AsianPacific region (0 out of 265 samples), which agrees with our findings, although a $6 \%$ contamination ( 1 out of 18 samples) was found from the European region, with that sample containing $188 \mu \mathrm{g} / \mathrm{kg}$ (Binder et al., 2007). One positive corn sample (1 out 115 samples) at 104 $\mu \mathrm{g} / \mathrm{kg}$ was reported in Brazil during the 1994 to 1995 crop year (Rodríguez-Amaya and Sabino, 2002). Corn produced during a growing season of high temperature and low rainfall had $14 \%$ positive samples containing, on average, $4 \mathrm{~g}$ of T-2 toxin/g (Goertz et al., 2010). Frequent rainfall and moderate growing conditions resulted in $10 \%$ positive samples, with average mycotoxin concentration of $10 \mu \mathrm{g} / \mathrm{kg}$.

In the present study, ZEN was not detected in any corn samples. This finding differs from previous observations. Worldwide, $32 \%$ of 394 samples tested by ELISA were positive for ZEN (mean concentration $=41 \mathrm{mg} /$ kg; Rodrigues and Naehrer, 2012). In Europe, maize ear rot was associated with ZEN occurrence (Logrieco et al., 2002). In Germany, $27 \%$ of the corn samples were positive, with an average ZEN concentration of $70 \mu \mathrm{g} / \mathrm{kg}$ when growing conditions consisted of high temperature and low rainfall (Goertz et al., 2010). In contrast, in the subsequent growing season with moderate temperatures and frequent rainfall, $93 \%$ of the corn samples tested positive, with an average ZEN concentration of $480 \mu \mathrm{g} / \mathrm{kg}$. In Brazilian corn, 30.4\% (65 positive out of 214 corn samples) were contaminated with ZEN $($ mean $=155 \mu \mathrm{g} / \mathrm{kg}$; range $=36.8$ to $719 \mu \mathrm{g} / \mathrm{kg}$; Vargas et al., 2001) and Binder et al. (2007) reported that ZEN was a prevalent mycotoxin in corn. Forty-one percent (mean concentration $=463 \mu \mathrm{g} / \mathrm{kg} ; 128$ out of 312 samples) and $63 \%$ (mean concentration $=279 \mu \mathrm{g} /$ $\mathrm{kg}$; 59 out of 93 samples) of corn samples, depending on world region, were contaminated with ZEN, indicating that worldwide ZEN was more prevalent than what we observed in the present study and that growing conditions influence ZEN contamination of corn (Binder et al., 2007).

\section{CONCLUSIONS}

Our results confirm that mycotoxin contamination in corn is a common occurrence and requires careful surveillance to prevent exposure to potentially harmful concentrations. From this pilot study, fumonisins, aflatoxins, and DON are of greatest concern due to their confirmed presence in California corn and their known effects on livestock. With the exception of 1 sample, whole corn samples had levels below the FDA regulatory limits. The relative risk exposure to livestock was low during the time period in which data were collected. However, it is possible that synergistic effects of various mycotoxins or other nutrients and metabolites may pose additional risk to animal health and changing environmental conditions in the Midwest growing regions warrant additional surveillance. Having a clear understanding of occurrence and levels in corn fed to dairy cattle is critical for implementation of prevention strategies and managing mycotoxin contamination in grain. Thus, based on these initial findings, whole corn entering California should be routinely monitored for mycotoxins to ensure a supply of safe feed is fed to animals that are producing food for humans.

\section{REFERENCES}

Balázs, E., and J. S. Schepers. 2007. The mycotoxin threat to food safety. Int. J. Food Microbiol. 119:1-2.

Binder, E. M., L. M. Tan, L. J. Chin, J. Handl, and J. Richard. 2007. Worldwide occurrence of mycotoxins in commodities, feeds and feed ingredients. Anim. Feed Sci. Technol. 137:265-282.

Bryden, W. L. 2012. Mycotoxin contamination of the feed supply chain: Implications for animal productivity and feed security. Anim. Feed Sci. Technol. 173:134-158.

Caldas, E. D., and A. C. S. Silva. 2007. Mycotoxins in corn-based food products consumed in Brazil: An exposure assessment for fumonisins. J. Agric. Food Chem. 55:7974-7980.

California Grain Foundation. 2005. Evaluating Marketing Opportunities for California Corn Producers. California Grain Foundation, California Wheat Commission, Woodland, CA.

CDFA (California Department of Food and Agriculture). 1997. Agricultural Commodities and Regulatory Services Inspector's Manual. Pages 33-34. California Department of Food and Agriculture, Sacramento, CA.

Cothern, J. H. 2000. Wheat and feed grains outlook. Pages 1-8 in Proc. 19th Annual Agribusiness Management Conference. Center for Agriculture Business, Fresno, CA.

De Saeger, S., L. Sibanda, A. Desmet, and C. Van Peteghem. 2002. A collaborative study to validate novel field immunoassay kits for rapid mycotoxin detection. Int. J. Food Microbiol. 75:135-142.

Driehuis, F., M. C. Spanjer, J. M. Scholten, and M. C. te Giffel. 2008. Occurrence of mycotoxins in feedstuffs of dairy cows and estimation of total dietary intakes. J. Dairy Sci. 91:4261-4271.

Goertz, A., S. Zuehlke, M. Spiteller, U. Steiner, H. W. Dehne, C. Waalwijk, I. de Vries, and E. C. Oerke. 2010. Fusarium species and mycotoxin profiles on commercial maize hybrids in Germany. Eur. J. Plant Pathol. 128:101-111.

González-Osnaya, L., J. M. Soriano, J. C. Moltó, and J. Mañes. 2008. Simple liquid chromatography assay for analyzing ochratoxin A in bovine milk. Food Chem. 108:272-276.

Logrieco, A., G. Mulè, A. Moretti, and A. Bottalico. 2002. Toxigenic Fusarium species and mycotoxins associated with maize ear rot in Europe. Eur. J. Plant Pathol. 108:597-609.

Magan, N., and D. Aldred. 2007. Post-harvest control strategies: Minimizing mycotoxins in the food chain. Int. J. Food Microbiol. 119:131-139.

Magnoli, C. E., A. L. Astoreca, S. M. Chiacchiera, and A. M. Dalcero. 2007. Occurrence of ochratoxin A and ochratoxigenic mycoflora in corn and corn based foods and feeds in some South American countries. Mycopathologia 163:249-260.

Ono, E. Y. S., Y. Sugiura, M. Homechin, M. Kamogae, É. Vizzoni, Y. Ueno, and E. Y. Hirooka. 1999. Effect of climatic conditions on 
natural mycoflora and fumonisins in freshly harvested corn of the State of Paraná, Brazil. Mycopathologia 147:139-148.

Rheeder, J. P., W. F. O. Marasas, and H. F. Vismer. 2002. Production of fumonisin analogs by Fusarium species. Appl. Environ. Microbiol. 68:2101-2105.

Richard, J. L. 2007. Some major mycotoxins and their mycotoxicoses-An overview. Int. J. Food Microbiol. 119:3-10.

Richard, J. L., G. A. Payne, A. E. Desjardins, C. Maragos, W. P. Norred III, J. J. Pestka, T. D. Phillips, H. P. van Egmond, P. J. Vardon, T. B. Whitaker, and G. Wood. 2003. Mycotoxins: Risks in Plant, Animal, and Human Systems. Vol. 139. Council for Agricultural Science and Technology (CAST), Ames, IA.

Rodrigues, I., and K. Naehrer. 2012. Prevalence of mycotoxins in feedstuffs and feed surveyed worldwide in 2009 and 2010. Phytopathol. Mediterr. 51:175-192.

Rodríguez-Amaya, D. B., and M. Sabino. 2002. Mycotoxin research in Brazil: The last decade in review. Braz. J. Microbiol. 33:1-11.

Scott, P. M. 2012. Recent research on fumonisins: A review. Food Addit. Contam. Part A: Chem. Anal. Control Expo. Risk Assess. $29: 242-248$.
Shephard, G. S., F. Berthiller, J. Dorner, R. Krska, G. A. Lombaert, B. Malone, C. Maragos, M. Sabino, M. Solfrizzo, M. W. Trucksess, H. P. van Egmond, and T. B. Whitaker. 2010. Developments in mycotoxin analysis: An update for 2008-2009. World Mycotoxin J. $3: 3-23$.

Spanjer, M. C., P. M. Rensen, and J. M. Scholten. 2008. LC-MS/MS multi-method for mycotoxins after single extraction, with validation data for peanut, pistachio, wheat, maize, cornflakes, raisins and figs. Food Addit. Contam. Part A: Chem. Anal. Control Expo. Risk Assess. 25:472-489.

Vargas, E. A., R. A. Preis, L. Castro, and C. M. G. Silva. 2001. Cooccurrence of aflatoxins $\mathrm{B}_{1}, \mathrm{~B}_{2}, \mathrm{G}_{1}, \mathrm{G}_{2}$, zearalenone and fumonisin $\mathrm{B}_{1}$ in Brazilian corn. Food Addit. Contam. 18:981-986.

Wild, C. P., and Y. Y. Gong. 2010. Mycotoxins and human disease: A largely ignored global health issue. Carcinogenesis 31:71-82.

Yiannikouris, A., and J. P. Jouany. 2002. Mycotoxins in feeds for ruminants; fate and effects on animals. Prod. Anim. 15:3-16. 